\title{
Dignity and Stigma among South African Female Cash Transfer Recipients
}

\author{
Tessa Hochfeld and Sophie Plagerson*
}

\begin{abstract}
This study analyses impacts of social discourses on the outcomes of social policy, through the narratives of female cash transfer recipients in Soweto, South Africa. Their understandings of poverty and welfare are related in complex and dynamic ways. Cash transfers are revealed as a tool of survival which helps to alleviate stigma associated with poverty. While recipients acknowledge that negative mainstream discourses on grant receipt are unjust, at the same time, they apply them to other recipients. We conclude that it is critical to support not only the material livelihoods of cash transfer recipients but also their human dignity, by investing in building rights-based policy environments.
\end{abstract}

\section{Introduction}

Social justice is realised in human dignity; and social protection can provide material assistance in ways that uphold human dignity or undermine it. This article is informed by an understanding that social justice is only achieved in social protection when welfare beneficiaries do not have to choose between their sense of dignity and their need for material assistance.

Underlying ideologies of poverty and welfare profoundly affect how social protection is designed, implemented, received and understood (Devereux and White 2010). In line with conservative ideologies, the poor are often portrayed as needy due to their own inadequacies and lack of work ethic, as irresponsible and undeserving of state assistance. The social imperative to be 'self-reliant' means that receiving welfare benefits is looked down upon and stigmatised. It is well-established in literature on social policy that the provision of welfare benefits to individuals is often accompanied by a rise in negative discourses about the recipients (Albelda 2001; Gordon 1994).

However, analysis of this phenomenon mostly takes place in high-income contexts where the state is trying to rationalise welfare services, and where welfare recipients form a small minority, often sharing group characteristics that make it easy to create stereotypes (e.g. young Black lone mothers in the USA). As cash transfers in the global South extend their reach, especially in Africa, and reach maturity, especially in Latin America, reflections on stigma and other social discourses about recipients will aid a deeper understanding of their social impact in contexts of widespread poverty and inequality.

South Africa is a middle-income country with high levels of inequality, widespread poverty and mass unemployment. A large-scale cash transfer programme is the state's most successful poverty alleviation strategy. The Child Support Grant (CSG) was introduced in 1997, at the height of the progressive drive of the new post-apartheid government. It is explicitly redistributive, providing 10.1 million poor children (identified via means testing) under 16 years of age with a monthly amount of R260 ( $\approx £ 20)$. A body of evaluative research concurs that 'the grant is reaching children living in households in deep poverty and has positive measurable impacts on, among other things, child nutrition and school attendance' (Lund 2011: 2). Concurrently, very clear negative discourses on social assistance receipt have emerged, namely assumptions that cash transfers create welfare dependency, and that the CSG encourages early and multiple

IDS Bulletin Volume 42 Number 6 November 2011 (c) 2011 The Authors. IDS Bulletin (C) 2011 Institute of Development Studies Published by Blackwell Publishing Ltd, 9600 Garsington Road, Oxford OX4 2DQ, UK and 350 Main Street, Malden, MA 02148, USA 
child-bearing. The erosion of the rights discourse in South Africa has had a clear impact on policy with, as an example, the recent introduction of school attendance as a conditionality for the CSG, despite almost universal primary school attendance. However, little is known about how welfare beneficiaries view themselves as recipients, and how these negative social discourses are interpreted in the light of their own and others' severe needs.

Investigating the social construction of welfare beneficiaries in South Africa can make an important contribution to the literature on the global South, as little has been written on stigma in these contexts. The study critically examines female C.SG beneficiaries' interpretations of public attitudes towards them, as well as their views on poverty and their own rationalisations of why they and others receive the grants. From a social justice perspective, this article seeks to unpack some of the complexities of welfare receipt, in order to inform the long-term design of social protection programmes in ways that enhance recipients' dignity and autonomy.

\section{Methods}

The study draws on data collected in Doornkop, an urban community in Soweto, Johannesburg.

The area represents the poorest municipal ward in the region and consists of government housing and informal shacks. While poor, Doornkop residents all have outdoor access to piped water on their stands and the area is fully electrified. Primary schooling is free, and free health services are available to pregnant women and children under six years. This 'basket' of state services is of tremendous value to the community. Nevertheless, it does not change the economic status of the people who live there: they are still largely unemployed and poor. The chronic lack of stable household income means that over 80 per cent of women in Doornkop who look after children under the age of 16 years receive one or more CSGs (Patel and Hochfeld 2011).

We interviewed eight women from 344 names on a database of women receiving CSGs (Patel and Hochfeld 2011). These eight women were purposively selected to represent different ages, number of CSGs and housing types. The interviews covered women's everyday experiences of the grant, reasons for needing the grant, how they characterise grant recipients, and their views on poverty, social assistance and public discourses on the grant.

The eight women were aged 23-60 years old. Six of the eight lived in small concrete or brick structures, with one room for sleeping and one for living and cooking. Two women lived in backyard shacks. While small and stiflingly hot due to the metal roofing, these homes were furnished and very neat and clean. All the homes had indoor electricity, and outdoor piped water and toilets (only one had water piped inside the house).

While the women looked after between one and five children each, none received more than two grants. The reasons range from children being too old to be eligible, children who are staying only temporarily in the home, to the difficulties of getting the correct documentation to apply for the grant. Two households had a young baby for whom the mother had not yet applied for a grant. Of the eight women, only two lived with partners and in most cases, the fathers gave little or no financial support to their children.

\section{3 'I don't want to be called poor. Who wants to be called poor?': poverty and stigma \\ 3.1 Definitions and causes of poverty}

Participants offered two main definitions of poverty. The first relates to the experience of poverty. Inability to feed and clothe oneself and one's children is considered a primary indicator of poverty. In these conversations, going to bed on an empty stomach was the most commonly used boundary between poor and not poor. Using this definition, participants generally did not describe themselves as poor. The CSG was spoken about as the critical mediator between these two states, supporting research that shows the grant intervenes to prevent severe nutritional deficits (Agüero et al. 2006).

Participants said the following:

Since I never slept on an empty stomach, no, I cannot say that I am poor. (Nosipho) ${ }^{1}$

Poverty is just seeing the child poor, not being the same as the other child even when they play... since they are now hungry... [Since receiving the grant] he is no longer hungry, their stomach is full since they are receiving the food... there is no poverty anymore. (Margaret) 
A second definition related to the causes of poverty and its equation with unemployment. Unemployment was viewed as a structural issue, beyond the control of those affected. Respondents often spoke of their struggles to find work.

There is a lot of poverty here in South Africa, many people are struggling, they are not working'. (Pumla)

This money that they are receiving [the CSG], [it is because] they are not employed, you find that they are not working, they do not have anything for their living, if you try to look for the job, you do not get it. (Zandile)

This was very pervasive as a theme.

Unemployment and poverty were understood as linked in a simple causal relationship, the former causing the latter. Under this definition, employment was viewed as providing a more sustainable route out of poverty in comparison with grants. Nosipho describes this relationship as follows:

I was working but I lost my job. But then when I was working, I could see what I was working for, I was able to buy within a year a TV, this one in this house, I bought this table in this house even though it just does not have chairs. I bought a room divider. Within one year I bought those things. On the second year I bought a fridge just this one which is now dilapidated, do you understand? Only two years but... I could see what I worked for so I am telling myself that the government, this money... he should rather give us employment. (Nosipho)

The grant is seen as interacting with different definitions of poverty in different ways. On the one hand, recipients are mostly poor if poverty is defined as unemployment; but, on the other, grants assist in preventing indigence and hunger. Understandings of poverty seemed to swing between these meanings in the progression of women's narratives, although the meaning of unemployment predominated. Consequently, women believed that the CSG saves people from starvation but cannot change people's socioeconomic position.

\subsection{Poverty and agency}

Structural explanations of poverty did not rule out the role of coping strategies: women believed the movement out of poverty requires both structural changes (more jobs) as well as individual responsibilities (women have the responsibility to look for or create some form of income). Women expressed this in the following ways:

Since they are receiving the grant, it does not mean that your hands have been chopped such that you cannot go out and look for work, as I am saying that there are... temporary jobs, maybe you are working as a domestic worker, maybe you go around doing the washing for people, something like that. (Thandeka)

I do not want to sit and depend on it, I also want to have something that is entirely mine, the wages. (Victoria)

Therefore coping was not just having resources, it was also about generating resources oneself, and then feeling in control over the decisions on how to consume them, echoing the philosopher Amartya Sen's (1999) ideas that choice and control are central to genuinely having a life of value and dignity. Individual coping strategies, particularly in the vein of the notion of 'selfreliance', was a theme in many of the younger women's stories. They spoke about how the grant can be a 'step-up' in more ways than just to buy food for the family, and it was striking how much their language echoed the state's strong discourse of self-sufficiency, for example:

\section{I rather take this assistance and break it down in a manner that I think it can help me you see, at the same time being on the look-out for vacancies... Maybe if I had capital to do something for myself like a business, right, I would have done that to meet the government's grant half way. (Victoria)}

Get the money. You do something with it. Don't sit and complain and say it's not enough. (Mpho)

A sure route to good paid employment was consistently described as education. This combined with a powerful belief in agency was responsible for the weak expectation of the intergenerational transmission of poverty. This is in marked contrast to research in developed contexts where women in welfare assume their descendents would be similarly trapped in poverty (Seccombe et al. 1998). Margaret commented:

Actually probably [the next generation of children] may not need it since perhaps [my grandchild] will 
study and get a job that will pay him well and be able to afford children, will raise them well, you see that his children will no longer receive the grant if that is the case. Yes, it [will be] different. (Margaret)

Therefore, grants are a tool in the women's survival strategies; they contribute to a sense of power and control, and are a step towards independence. On their own, however, grants cannot change women's social conditions. Women believe strongly that while poverty is structurally caused, overcoming it is in the hands of the individual and what they do with the slim resources at their disposal.

\subsection{Stigma of poverty and the limits to agency}

In the context of an understanding of poverty that was overwhelmingly structural, there was a strong sense of a common poverty, the cause of which was shared. Yet, while a structural understanding of poverty implies that being poor is not the fault of the individual, it was striking how many respondents who had a clear, technical, non-emotive and non-blaming definition of poverty (lack of employment), nevertheless felt shame and discomfort when applying the label to themselves. They overwhelmingly preferred not to be called poor. This is evocatively described by one respondent in the following exchange:

Mpho: [CSG recipients] don't see themselves as poor. They are poor, they don't want to be... It's like calling names, you are saying, you are poor like if you are gossiping about that person. They do not like that.

Interviewer: Would you say the same about yourself?

Mpho: I would say so about myself, I don't want to be called poor. Who wants to be called poor?

Interviewer: Well you can say you may want to be called poor so you can receive [a grant]?

Mpho: No. If they want to cut the grant because I don't want to be called poor they can do that.

The focus placed on individual coping mechanisms and the value assigned to selfreliance provide a key to understanding the perceived stigma associated with being poor. Grants were seen as a tool to counteract the shame associated with not being able to provide for one's children. They offered a more dignified form of assistance and support to one's limited livelihood strategies, compared to the stigma associated with unequal and disempowering dependence on family and community networks. One respondent described the positive psychological impact of the grant as follows:

Interviewer: If you look at [a friend also getting a CSG], do you think that she was poor?

Margaret: Not that she was poor as such but if there is no hand that is helping you, you see, just psychologically there used to be something that was just not going well with her, why are you not getting the grant for your child, why am I not able to live like other women... so the grant assisted her a lot [because] after receiving it that [shame and anxiety] came to an end, I also noticed that she was in good health now being able to think, being able to live just a normal life.

Another respondent's description of how the grant protects her family both from hunger and dependency on her neighbours was typical of other's experiences too:

I opted for a grant... so that we do not sleep on empty stomachs, so that children do not sleep on empty stomachs and end up going to the neighbours and being a problem to the neighbours asking for food. (Pumla)

\section{4 'Those who don't have the grant look down on those who get the grant': grants and stigma 4.1 Grants and the state}

Grants were viewed not as an obligatory governmental response to structural labour market failures but as a generous support to personal coping mechanisms in the face of poverty. As a result, only weak notions of entitlement to social security were expressed in interviews. Women typically expressed gratitude that they were receiving the grant. In this context, they spoke of the state as a benevolent carer who sees their plight and that of their children.

It [the government] does give people the grant, maybe it can see that they are poor. (Zandile)

A number of women spoke explicitly about the CSG as a 'gift' rather than a 'right', raising the issue of grant insecurity. Women worried that the state will withdraw the favour in the future, either because the state might 'run out of money' or that it will stop the grant due to persistent misuse; women were thus anxious that 
they might have to pay for others' mistakes or misuse. For example:

It's something that is a present, you have been given, you cannot say maybe you are... you are complaining or what... Actually I think that [the CSG] will cease to exist. If the government is going to... provide for the child, ja, I think that [the money] will be used up. (Nosipho)

The 'right' to grants was only mentioned in one instance, with a negative connotation by a recipient who judged that citizenship provided, in her view, non-poor claimants with an unethical basis for grant receipt. Her comment implied that her own appreciation for the grant was a more appropriate response:

There is no time to play. Even if you can rely on something that offers you money... I just never told myself that it will work for me. Actually, I do appreciate it when it is being presented to me. [But] I need to work and add on it. So I did see that other people are not suffering, they are not in need of it. It's just that because they are South African citizens they have that right... So it's not only poor people who are getting grants, even people who are right [not poor] they receive the grant. (Victoria)

\subsection{Grants, stigma and individualism}

The greater emphasis on individual coping mechanisms to exit poverty tended to override the acknowledgement of the structural causes of poverty, when recipients talked of others' grant receipt. While they described themselves as deserving, they were surprisingly quick to categorise others as undeserving of grants. This is despite their keen awareness of how negative discourses on welfare stigmatise the GSG and therefore reflect negatively on them personally. For example:

Those who don't have the grant look down on those who get the grant, they are saying like they are lazy, they don't want to work and then they have to wake up early in the morning and do stuff for themselves, they don't have to depend on anyone. Forgetting if they were in the same situation as those who get the grant they wouldn't say that. So they don't know the situation. (Mpho)

People are aware of it [the CSG]. It's just that another person can see themselves such that if I can go and apply for a grant I will be degrading myself...
Now ifyou explain to them that you see one, two, three it will help you, they open up, something is revealed to them and they then go and apply also. (Margaret)

Therefore while in the above quotes the women were able to identify the injustice of being stigmatised unfairly, they tended to do the same to other grant recipients. In contrast with the lack of differentiation between 'me' and 'them' in women's definitions of poverty, there was a strong differentiation in relation to welfare receipt; 'me' identifying with structural causes of welfare receipt and 'them' relating far more to individualist explanations leading to blame and stigma. Laziness, irresponsible spending of the grant and reckless childbearing were behaviours associated with being undeserving of the grant. For example, none of the women believed that they themselves were lazy, but some did think that the grant assisted other people to take no initiative.

I can say others, they get spoilt, right, in such a way a person does not think of doing something right, that they can do... to back the grant up, you see. It means there are people who are relaxing, who are seated, who do not care... They are lazy anyway since actually there is nothing else that they are thinking of, they wait for that pay day, that day of the grant. (Victoria)

It is paradoxical that these observations can simultaneously be recognised as deeply unjust when applied to themselves. Victoria, the same respondent who complained about lazy beneficiaries, also expressively articulated the way in which such views could cause distress when experienced directly:

So even me also you know [the community think]... that I'm in that group that doesn't care anymore, who's abusing the grant, [because] I'm not working, I'm unemployed and it's many years now. It's seven or eight years, you see. And that thing is hurting me, okay? So somebody who is looking at me from a distance, cannot see what I'm thinking about or I'm not sleeping at night trying to change my situation. You see, you cannot see that, he or she would say 'she's relaxing; she's not looking for any job now', you see, 'because she's getting the grant. Maybe that grant is enough for her'. And yet it's not. (Victoria)

Thus, women both bought into and simultaneously rejected discourses of stigma, 
which implies while these discourses are both powerful and pervasive, they are also vulnerable to rejection in the face of individuals attempting to maintain their dignity.

\section{Discussion}

The data demonstrated a complex relationship between poverty and welfare in recipient discourses. The women in this study all explained poverty from a structural perspective, i.e. caused by a lack of jobs and not by personal deficiencies. Coherent with this is their belief in the logic that poverty leads to a need for the grant, not the other way around, where receiving the grant would identify you as poor. Compared with literature on grant recipients from the West, there is a stronger sense of shared difficulties - 'we are all poor' - and a belief that in the main, those who get the grant are receiving it for similar reasons.

Nevertheless, while being poor is perceived to be devoid of blame, the women still experience levels of shame. Poverty is seen as undignified and shameful, partly internally as women feel that poverty robs them of their ability to be the parents they want to be (providing for their children), as well as socially, as poverty forces them into degrading and embarrassing dependence on others in their family and community. These two levels of shame are a source of stigma, and derive from the limitations on agency that poverty imposes. In this context, grants are seen as offering a dignified way to provide for one's household and therefore serve to alleviate the stigma associated with poverty. The relationship between the CSG and improved autonomy and independence demonstrates a significant break from the widely held belief in both the developed and the developing world that cash transfers create dependency.

The grant, however, is not seen to be an absolute solution to poverty and in women's discourses 'structuralism' in relation to the cause of poverty coexists with far more 'individualist' language in relation to escaping poverty. The women believed that one has the personal responsibility to get out of poverty if one can, and doing this requires individualised exertion and inventiveness in livelihood choices initiated via the use of the grant. Further, women assumed there would not be an intergenerational transmission of poverty because their individual efforts and the efforts of their children were enough to disrupt or overcome structural causes of poverty. Hence, women believed there were genuine opportunities for moving up in social position, given individual effort and education. We maintain that this is one of the greatest differences between the South African context and welfare recipients in industrialised contexts, where women assume their children will face similar challenges and will also be poor and on welfare (Seccombe et al. 1998). However, while this belief in individual progress was pervasive, women's actual experiences also demonstrated the limitations imposed on their individual efforts by powerful structural disadvantages.

Individualism was apparent in another sense, too: respondents were universally aware of negative mainstream discourses about the CSG that portrayed grant recipients as lazy, immoral or irresponsible, all deriving from notions of individual blame. While acknowledging the largely unfounded premise for the accusations, women did not outright contradict them but rather splintered their observations into 'us' and 'them' categories, retaining popular mainstream moralistic discourses to talk of others receiving the grant, while applying structural constructions to explain their own need for and use of grants. While they identify with the circumstances that they share with other recipients, the lack of sense of entitlement to the grant and the pervasiveness of moralistic discourses on grant receipt encourages them to, at the same time, disapprove of grant receipt for certain women, contributing to existing stigma. Thus, the stigmatising public discourses surrounding the grant clearly permeate the conversations of even the poor themselves and create a complicated situation, whereby recipients need to reinterpret their identity and negotiate their dignity in various ways.

A partial explanation of the structuralist/ individualist mix described above can be found in the women's belief that grants are seen as a kind response to poverty by the state, not as a delivered entitlement. This lack of a clear rights discourse to the grant is a result of the coexistence of conservative and progressive ideologies in social policy discourses in South Africa and the influence of the global neoliberal discourse on how independence from the state is a righteous goal. The vacuum created by a lack of a sense of entitlement allows negative discourses to flourish. 
From a social justice perspective, receiving the Child Support Grant leads to a subsequent tradeoff for women: the grant offers dignity that poverty denies them and releases them from unwanted dependence on others, but at the same time, they may be forced into actively defending their dignity from pervasive negative discourses, which have become increasingly hostile to expansive social protection measures in South Africa. Simultaneously, they unwittingly feed these very same stigmatising notions by repeating them about others. While overall women's social vulnerabilities are indubitably reduced via grant receipt, it is important to acknowledge that they

\section{Notes}

* Grateful thanks to the women who shared their stories with us so openly and willingly. Many thanks also to Nhlanhla Jordan who was a most warm, sensitive and competent

\section{References}

Agüero, J.M.; Carter, M.R. and Woolard, I. (2006) The Impact of Unconditional Cash Transfers on Nutrition: The South African Child Support Grant, Cape Town: Southern Africa Labour and Development Research Unit, University of Cape Town

Albelda, R. (2001) 'Welfare-to-Work. Farewell to Families: US Welfare Reform and Work/Family Debates', Feminist Economics 7.1: 119-35

Devereux, S. and White, P. (2010) 'Social Protection in Africa: Evidence, Politics, and Rights', Poverty and Public Policy 2.3: 53-77

Gordon, L. (1994) Pitied But Not Entitled: Single Mothers and the History of Welfare 1890-1935, New York: Free Press can be exposed to vulnerabilities other than poverty in the process of trying to manage their income deficiencies via a cash transfer.

More broadly, this study illustrates how social discourses on cash transfers can interact with recipient self-perceptions; and how this interaction shapes the social impact of the grant itself. It is important to continually monitor these processes, perceptions and social nuances, as this will influence whether the provision of material assistance through cash transfers will contribute to or detract from a recipient's sense of dignity.

interviewer. The feedback from the CSDA writing group and the Wits/UJ women's writing group was extremely helpful in shaping the ideas in this article.

1 All interviewee names have been changed.

Lund, F. (2011) 'A Step in the Wrong Direction: Linking the South Africa Child Support Grant to School Attendance', Journal of Poverty and Social Justice 19.1: 5-14

Patel, L. and Hochfeld, T. (2011) 'It Buys Food but Doesn't Change Gender Relations: Child Support Grants in Soweto, South Africa', Gender and Development 19.2: 229-40

Seccombe, K.; James, D. and Battle Walters, K. (1998) "“They Think You Ain't Much of Nothing": The Social Construction of the Welfare Mother', Journal of Marriage and the Family 60.4: 849-65

Sen, A. (1999) Development as Freedom, Oxford: Oxford University Press 